\title{
Dissipação do thiamethoxam e sua influência nos teores de fenóis em Hedychium coronarium J. Koenig
}

\author{
Dissipation of thiamethoxam and its influence on phenol levels in Hedychium \\ coronarium J. Koenig
}

\author{
Claudine Gonçalves Rocha ${ }^{1}$, Silvia Cristina Heredia Vieira ${ }^{2}$, Yzel Suarez Rondon ${ }^{3}$ e \\ Claudia Andrea Lima Cardoso ${ }^{4}$
}

1,2,3,4 Universidade Estadual de Mato Grosso do Sul - UEMS, Brasil

\begin{abstract}
Resumo
O crescimento da agricultura sobre os ambientes naturais tem levado várias espécies vegetais à exposição aos inseticidas, sem que seu papel na fisiologia destes organismos seja conhecido. O objetivo deste estudo foi avaliar os teores de thiamethoxam e determinar sua influência nos teores de fenóis totais e no perfil cromatográfico das folhas e rizomas de Hedychium coronarium. As plantas de H. coronarium foram expostas a duas concentrações de thiamethoxam em ambiente controlado, com aplicação através de pulverização. O inseticida foi detectado nas folhas durante os 26 dias de experimento, mas não nos rizomas. Os teores de thiamethoxam apresentaram uma redução acentuada nas folhas no decorrer do experimento. Os teores de fenóis totais sofreram influência da presença do thiamethoxam. A similaridade na frequência dos picos no perfil cromatográfico das folhas e rizomas demonstrou a influência do inseticida, onde nos rizomas essa influência ficou mais evidente na concentração de $190 \mathrm{mg}$ L-1.
\end{abstract}

Palavras-chave: Lírio-do-brejo. Inseticida, CLAE

\begin{abstract}
The growth of agriculture over natural environments has led to the exposition of several plant species to pesticides without the due knowledge of their effects on the physiology of these organisms. The objective of this study was to evaluate the effect of different levels of thiamethoxam on the levels of total phenols and on the chromatographic profile of Hedychium coronarium leaves and rhizomes. The plants of $H$. coronarium were exposed to two concentrations of thiamethoxam in a controlled environment with the application of spraying. The pesticide was detected in leaves during the first 26 days of experiment, but not in rhizomes. The levels of thiamethoxam showed an important reduction in the leaves during the experiment. The levels of total phenols were affected by the presence of thiamethoxam. The similarity in the frequency peaks in the chromatographic profile of the leaves and rhizomes showed the influence of the insecticide, in which this influence in rhizomes was more evident in the concentration of $190 \mathrm{mg} \mathrm{L}-1$.
\end{abstract}

Keywords: Lírio-do-brejo. Inseticid, HPLC 


\section{Introdução}

$\mathrm{O}$ crescimento populacional acentuado levou à procura de maior produção agrícola e mostrou a necessidade de evitar perdas excessivas desta produção. Neste sentido, estão sendo incentivados estudos relacionados à contaminação, de forma a prevenir os problemas do meio ambiente gerados pela aplicação incorreta ou excessiva de agrotóxicos (Pussente, 2008).

Com a implantação de novas indústrias sucroalcooleiras no estado de Mato Grosso do Sul, ocorre o aumento de áreas de cultivo de cana-de-açúcar, ocasionando o risco de contaminação por inseticidas, principalmente no ato da pulverização aérea. Inseticidas neonicotinóides possuem um amplo espectro de atividade, sendo essa, uma das características que fez com que sejam utilizados para substituir outras classes de inseticidas, que se mantiveram no topo do mercado internacional por muito tempo (Kima et al., 2006).

Inseticidas são utilizados em tratamentos de sementes para controlar a presença de insetos, pragas do solo, além de poder interferir na germinação das sementes e no crescimento de plantas jovens. O thiamethoxam é uma destas alternativas, já que foi capaz de aumentar os índices de germinação e o vigor das plantas quando empregaram-se sementes tratadas com este inseticida (Carvalho et al., 2011).

O thiamethoxam é um inseticida de ação sistêmica, do grupo dos neonicotinóides, sendo composto por 3- (2 - cloro - tiazol - 5 - ilmetil) - 5 - metil - [1,3,5] oxadiazinan -4 - ilideno $-\mathrm{N}$ - nitroamina, uma classe toxicológica de nível III, medianamente tóxico, que possui baixa toxicidade para mamíferos, aves e peixes, mas, para alguns insetos, como as abelhas, é prejudicial, já que atua nos receptores niconíticos (Rancan et al., 2006).

Macedo e Castro (2011) sugerem que a molécula de thiamethoxam pode também desempenhar um papel regulador do crescimento, alterando positivamente a fisiologia da planta. Isso porque, em experimento em estufa com doses de thiamethoxam, observaram que este influenciou no crescimento inicial da planta, alterou a distribuição de fotoassimilados, aumentou a concentração de proteína solúvel total e reduziu a atividade do nitrato redutase.

O thiamethoxam, em condições fotolíticas, sofre rápida degradação (Schwartz et al., 2000). Esse inseticida, em águas residuais no escuro, em condições anaeróbicas, sofreu um processo de biodegradação mais lenta quando comparado ao inseticida exposto à luz natural (Peña et al., 2011). Em estudo realizado por Liqing et al. (2006), em que avaliou-se a hidrólise do thiamethoxam, foi possível constatar que o mesmo degrada rapidamente em $\mathrm{pH}$ mais elevado ( $\mathrm{pH} \mathrm{10})$, em temperatura controlada $\left(25^{\circ} \mathrm{C}\right)$.

A fotodegradação é um dos caminhos mais destrutivos para pesticidas, principalmente nas superfícies das folhas e, também, pode ocorrer na superfície do solo se a planta não sombrear o mesmo (Katagi, 2004). Com a busca por compostos capazes de diminuir os insetos que prejudicam a produção agrícola, foi acentuada a utilização de pesticidas no meio ambiente. Assim, estudos de fitorremediação tornaram-se a opção mais viável economicamente, pelo baixo custo operacional (Lamego e Vidal, 2007).

As macrófitas enraizadas foram definidas como um grupo potencialmente útil para fitorremediação e controle biológico, uma vez que são capazes de absorver poluentes através de suas raízes imersas no solo (Biernack e Lovett-Doust, 1997) e, também, em colunas de água (Everard e Denny, 1985).

Hedychium coronarium J. Koenig, pertencente à família Zingeberiaceae, é uma macrófita aquática exótica, nativa da região do Himalaia, na Ásia tropical, e possui diversos nomes comuns, incluindo borboleta gengibre e lírio-do -brejo (Matsuda et al., 2002; Santos et al., 2005). A espécie tem capacidade de biorremediação em purificação de esgoto, além de ser eficiente na remoção de coliformes fecais e totais (Almeida e Almeida, 2005), de nitrogênio amoniacal, nitrito, nitrato e fosfatos (Almeida et al., 2007).

O potencial remediador de H. coronarium e sua presença em bordas de córregos, associados à aplicação do inseticida thiamethoxam na agricultura regional, tornam de grande importância este estudo. Com a realização desse trabalho objetivou-se verificar a concentração de thiamethoxam em folhas e rizomas de H. coronarium e em amostras de água e solo, além de determinar a influência deste inseticida no perfil cromatográfico e nos teores de fenóis totais em folhas e rizomas da espécie.

\section{Materiais e Métodos}

A água destilada e deionizada foi ultra purificada empregando um sistema da marca Human UP 900/ Scholar-UV, com seis colunas de troca iônica, lâmpada germicida 185/254 nm, filtro de carvão ativado e filtro de saída de $0,22 \mu \mathrm{m}$. O padrão de thiamethoxam $(99,7 \%)$ foi obtido da Sigma-Aldrich, álcool metílico grau cromatográfico da VETEC e ACTARA 250 WG da Syngenta (composição: thiamethoxam $250 \mathrm{~g} \mathrm{~kg}^{-1} \mathrm{e}$ ingredientes inertes $750 \mathrm{~g} \mathrm{~kg}^{-1}$ ).

A solução estoque de thiamethoxam foi diluída em água e, em seguida, foram realizadas diluições, obtendo-se soluções com concentrações de 1,2 a $192 \mu \mathrm{g} \mathrm{L}^{-1}$, as quais foram utilizadas para construção da curva analítica.

As análises foram realizadas empregando-se a técnica de cromatografia líquida de alta eficiência (CLAE), em que utilizou-se equipamento da Shimadzu LC-6AD, detector UV-Vis-SPD-AV, coluna de fase reversa C-18 (Phenomenex Gemini, $25 \mathrm{~cm} \times 4,6 \mathrm{~mm} \times 5 \mu \mathrm{m}$ ). A fase móvel utilizada para a eluição das amostras, água e solo, iniciou-se com água/metanol (60:40 v/v), permanecendo até $7 \mathrm{~min}$; em $23 \mathrm{~min}$, a concentração de metanol chegou a 100\%, retornando à condição inicial aos 35 min. Para 
rizomas e folhas, a fase móvel foi água/metanol (60:40 $\mathrm{v} / \mathrm{v}$ ) até $7 \mathrm{~min}$, em $23 \mathrm{~min}$, o metanol alcançou 100\% e, a condição inicial foi retomada aos $40 \mathrm{~min}$. Utilizou-se fluxo de $1 \mathrm{~mL} \mathrm{~min}^{-1}$, volume de injeção de $20 \mu \mathrm{L}$ e os comprimentos de onda monitorados foram 254 e $360 \mathrm{~nm}$.

As plantas e solo foram coletados em Dourados-MS nas coordenadas $22^{\circ} 09^{\prime} 24.2^{\prime \prime} \mathrm{S}$ e $54^{\circ} 57^{\prime} 08.5^{\prime \prime} \mathrm{W}$. A espécie foi identificada pela taxonomista vegetal Msc. Vali Joana Pott, sendo uma exsicata depositada no Herbário da UFMS com o número CGMS/31466.

O cultivo foi realizado em seis tanques $(n=6)$, sendo cada três considerados as repetições para uma dose do inseticida. Os tanques foram preenchidos com 100 $\mathrm{kg}$ de solo com umidade inicial de $60 \%$. Logo após o transplante dos brotos, adicionaram-se 20 L de água, por tanque, mantendo-se um microambiente similar ao do local de amostragem das plantas; a quantidade de água ao longo do experimento foi determinada de acordo com a necessidade.

As plantas permaneceram, em fase de adaptação, durante três meses, em casa de vegetação. Nesse período, houve a multiplicação de novos indivíduos e, ao final do período, as plantas alcançaram uma altura média de $20-30 \mathrm{~cm}$, sendo utilizadas no experimento as plantas com altura entre $25-30 \mathrm{~cm}$, com uma média de 25 indivíduos em cada tanque.

O inseticida thiamethoxam, diluído em água destilada, nas concentrações de $760 \mathrm{mg} \mathrm{L}^{-1}$ e $380 \mathrm{mg} \mathrm{L}^{-1}$, foi aplicado nos tanques, separadamente, resultando em uma concentração de $95 \mathrm{mg} \mathrm{L}^{-1}$ e $190 \mathrm{mg} \mathrm{L}^{-1}$ do thiamethoxam ativo, respectivamente. As doses de aplicação tiveram como referência a dose aplicada (1000 $\left.\mathrm{g} \mathrm{ha}^{-1}\right)$ para Mahanarva fimbriolata (Stal, 1854) em cultivo de cana-de-açúcar, já que este tipo de cultura é comum na região de estudo, devido à presença de indústrias sucroalcooleiras.

A aplicação foi realizada através de um pulverizador de plástico manual (500 mL), em movimentos circulares, sobre cada tanque. Nos tanques definidos como controle, não foi aplicado o inseticida e, durante a aplicação do thiamethoxam nos outros tanques, os controles foram cobertos por $30 \mathrm{~min}$. Após este período, houve uma aplicação de água destilada sobre cada tanque. Os experimentos foram realizados em duplicata.

Os indivíduos de $H$. coronarium foram numerados de 1-10 em cada tratamento e o material vegetal foi dividido em parte área (folha, $n=10$ ) e submersa (rizoma, $n=10$ ). As amostras de folhas foram padronizadas entre o terceiro e sexto nó, enquanto que para o rizoma, estabeleceu-se o corte de aproximadamente $1 \mathrm{~cm}$ em cada planta.

A duração do experimento foi de 54 dias, resultando em 10 coletas $(\mathrm{C} 1=01 \mathrm{~h}, \mathrm{C} 2=3$ dias, $\mathrm{C} 3=5$ dias, $\mathrm{C} 4=12$ dias, $\mathrm{C} 5=19$ dias, $\mathrm{C} 6=26$ dias, $\mathrm{C} 7=33$ dias, $\mathrm{C} 8=40$ dias, $\mathrm{C} 9=47$ dias, $\mathrm{C} 10=54$ dias após a aplicação do inseticida). As coletas foram determinadas de acordo com um teste inicial realizado, no qual foi possível verificar uma maior degradação do inseticida no início do experimento.
Para solo $(n=10)$ e água $(n=6)$ foram empregadas amostras aleatórias nos tanques, sendo que as amostras do solo e da água foram coletadas na superfície. As amostras foram colocadas em sacos plásticos de 15 × 25 $\mathrm{cm}$, com exceção da água, as quais foram colocadas em vidros (15 mL) com tampa de borracha e, em seguida, armazenadas em freezer a $-5^{\circ} \mathrm{C}$.

As amostras de solo foram secas em estufa de aquecimento a $40^{\circ} \mathrm{C}$ e uniformizadas em peneira de alumínio (malha $1 \mathrm{~mm}$ ).

Para a extração do material, foram colocados em contato $1 \mathrm{~g}$ de solo com $2 \mathrm{~mL}$ de água ultra purificada por $12 \mathrm{~h}$. Após este período, a mistura foi colocada em ultrassom (Ultrasonic Clean 1440 D, Odontobrás) por 40 min e filtrada em papel quantitativo $(8 \mu \mathrm{m})$. Ao material sólido adicionou-se $1 \mathrm{~mL}$ de água, permanecendo por 40 min em ultrassom e, em seguida, realizou-se novamente a filtração, sendo, este último processo extrativo, realizado em duplicata. O extrato obtido foi elevado em balão volumétrico de $10 \mathrm{~mL}$ e filtrado com membranas de 0,45 $\mu \mathrm{m}$ e, posteriormente, de 0,20 $\mu \mathrm{m}$ e, então, submetido às análises.

O preparo da amostra de água foi realizado colocando-se $1 \mathrm{~g}$ de água em contato com $2 \mathrm{~mL}$ de água ultra purificada por $1 \mathrm{~h}$ e, em seguida, a mistura foi deixada por 40 min em ultrassom. A amostra foi filtrada em papel quantitativo $(8 \mu \mathrm{m})$ e elevada em balão volumétrico de $5 \mathrm{~mL}$ sendo, posteriormente, filtrada em membrana de 0,20 $\mu \mathrm{m}$ e submetida às análises em CLAE.

Para a extração das folhas, colocaram-se $0,2 \mathrm{~g}$ de folhas em contato com $2 \mathrm{~mL}$ de água ultra purificada por 40 min em ultrassom. A amostra foi então filtrada em papel quantitativo $(8 \mu \mathrm{m})$ e o material sólido, extraído pelo mesmo procedimento por duas vezes consecutivas, substituindo o volume de água ultra purificada de 2 $\mathrm{mL}$ para $1 \mathrm{~mL}$. As frações foram unidas e elevadas em $5 \mathrm{~mL}$ em balão volumétrico, filtrada em membrana de $0,20 \mu \mathrm{m}$ e submetida às análises.

Os rizomas foram submetidos ao mesmo procedimento de extração efetuado nas folhas.

Todas as amostras que não apresentaram resposta dentro dos valores da curva analítica foram diluídas ou concentradas de acordo com a necessidade.

A eficiência de extração foi determinada através da análise de alíquotas das amostras fortificadas (1,2-95,7 $\left.\mu \mathrm{g} \mathrm{L}^{-1}\right)$, sendo estas, submetidas ao mesmo procedimento descrito para extração das amostras.

Para análise de fenóis totais em folhas e rizomas, empregou-se o método com o reagente Folin-Ciocalteau (Djeridane et al., 2006). A cada $100 \mu \mathrm{L}$ das amostras, adicionaram-se 1,5 mL de solução aquosa de carbonato de sódio 20\%, 0,5 mL de reagente Folin-Ciocalteau (1:10 v/v) e $1 \mathrm{~mL}$ de água destilada. Após $30 \mathrm{~min}$, a leitura foi realizada em espectrofotômetro (Femto 700 Plus) a 760 $\mathrm{nm}$. O mesmo procedimento foi realizado para o branco, sendo substituído os $100 \mu \mathrm{L}$ de amostra por $100 \mu \mathrm{L}$ de 
água ultra purificada.

Elaborou-se uma matriz de frequência dos picos cromatográficos das folhas e rizomas, em que foram comparados através da construção de uma matriz de similaridade utilizando o método de ligação UPGMA e distância Bray-Curtis, sendo o coeficiente de correlação cofenética utilizado como indicativo de fidelidade do dendrograma gerado a partir da matriz de similaridade. Todas as análises foram realizadas no software $R$ ( $R$ Development Core Team 2011).

\section{Resultado e Discussão}

As porcentagens de recuperação do thiamethoxam nas folhas variaram de 86,33 a $98,99 \%$, nos rizomas de 82,82 a $96,86 \%$, no solo de 82,65 a $99,01 \%$ e na água de 88,49 a $99,01 \%$. Em todos os experimentos, os coeficientes de variação (CVs) foram menores que 5\%, indicando uma boa recuperação com o método utilizado.

O thiamethoxam apresentou um tempo de retenção de $5,25 \pm 0,23 \mathrm{~min}$, nas condições cromatográficas avaliadas (Figura 1), onde, com a curva analítica (1,2-192 $\left.\mu \mathrm{g} \mathrm{L}^{-1}\right)$, obteve-se um coeficiente de determinação de 0,9996.

Para cada valor empregado nas Figuras 2, 3 e 4 foram obtidos uma média de réplicas de amostras. Os CVs dos teores de thiamethoxam na água foram todos abaixo de $15 \%$; por outro lado, no solo houve uma alta variação dos percentuais (16,35 a 74,05\%), possivelmente porque, no ato da aplicação, o inseticida chegou ao solo de forma heterogênea e, como a coleta foi aleatória, em algumas réplicas não houve detecção do thiamethoxam.

Nas folhas, houve uma variação nos CVs, sendo a maioria abaixo de $30 \%$. As réplicas foram por amostras, no caso das folhas, por indivíduo, portanto, isso explica os coeficientes serem altos, quando comparados com réplicas de extração que foram realizadas com o mesmo indivíduo que tiveram um coeficiente de variação $(\mathrm{CV})$ menor que $5 \%$.

No solo, o inseticida foi detectado até 12 dias para a concentração de $190 \mathrm{mg} \mathrm{L}^{-1}$ e 5 dias para $95 \mathrm{mg} \mathrm{L}^{-1}$ (Figuras $2 \mathrm{~A}$ e $2 \mathrm{~B})$. $\mathrm{O}$ thiamethoxam foi detectado nas amostras de água (Figuras 3A e 3B) e folhas (Figuras 4A e 4B) e, nos dois tratamentos, até 26 dias. Os teores de thiamethoxam apresentaram diminuição nos valores obtidos nas folhas, solo e água com o decorrer do experimento, sendo acentuada a diminuição da $1^{\text {a }}$ para a $2^{\text {a }}$ coleta.

A $1^{a}$ coleta foi realizada $1 \mathrm{~h}$ após a pulverização com o ACTARA $250 \mathrm{WC}$ e as folhas foram altamente expostas ao H. coronarium (Figuras 4A e 4B). Nas folhas, decorridos três dias da implantação do experimento, a redução foi em torno de 20 vezes no tratamento com 190 $\mathrm{mg} \mathrm{L}^{-1} \mathrm{e}$, de 25 vezes, no de $95 \mathrm{mg} \mathrm{L}^{-1}$ de thiamethoxam em relação a $1^{\text {a }}$ coleta das folhas. Da $2^{a}$ para a $3^{a}$ coleta, houve uma queda de $18 \%$ (190 $\left.\mathrm{mg} \mathrm{L}^{-1}\right)$ e de $12 \%$ (95 mg $\mathrm{L}^{-1}$ ) de thiamethoxam, nas folhas. Da $3^{\text {a }}$ para a $6^{\mathrm{a}}$ coleta, houve um intervalo de três semanas e a queda foi em torno de $80 \%$ nos tratamentos de $190 \mathrm{mg} \mathrm{L}^{-1}$ e $95 \mathrm{mg} \mathrm{L}^{-1}$ de thiamethoxam (Figuras 4A e 4B).

No solo, da $1^{\text {a }}$ para a $2^{\text {a }}$ coleta, a alteração na quantidade de thiamethoxam foi reduzida em relação ao que ocorreu na água e folhas, em torno de 39\% (190 mg L-1) e $48 \%$ (95 $\mathrm{mg} \mathrm{L}^{-1}$ ). Isso, possivelmente devido ao inseticida ter aderido às folhas (Figuras $4 \mathrm{~A}$ e $4 \mathrm{~B}$ ) pela forma de aplicação e/ou, na água (Figuras 3A e 3B).

Nas coletas realizadas aos 3 e 5 dias de implantação do experimento, a quantidade de inseticida presente no solo se manteve praticamente inalterada nos dois trata-

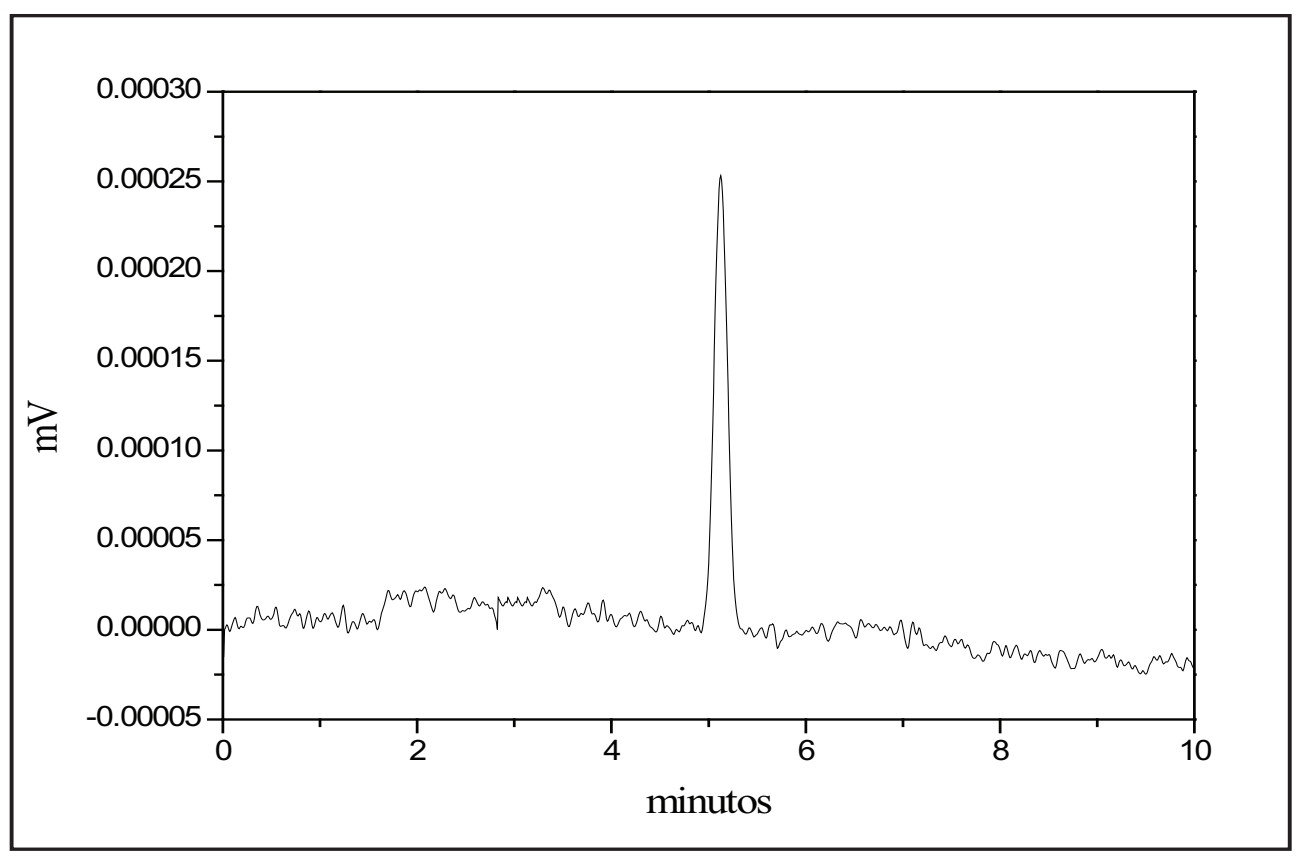

Figura 1 - Cromatograma do padrão de thiamethoxam 


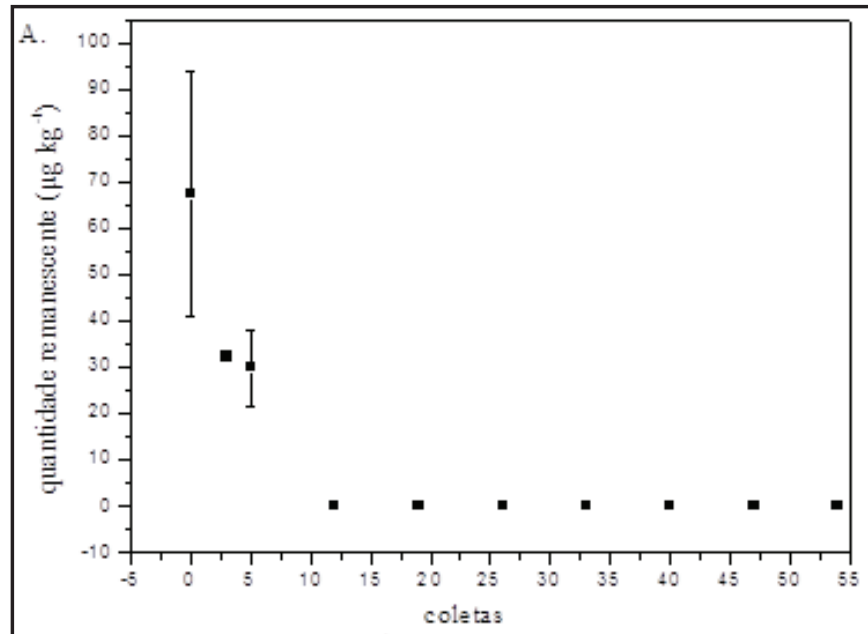

$95 \mathrm{mg} \mathrm{L}^{-1}$ de thiame thoxam ativo

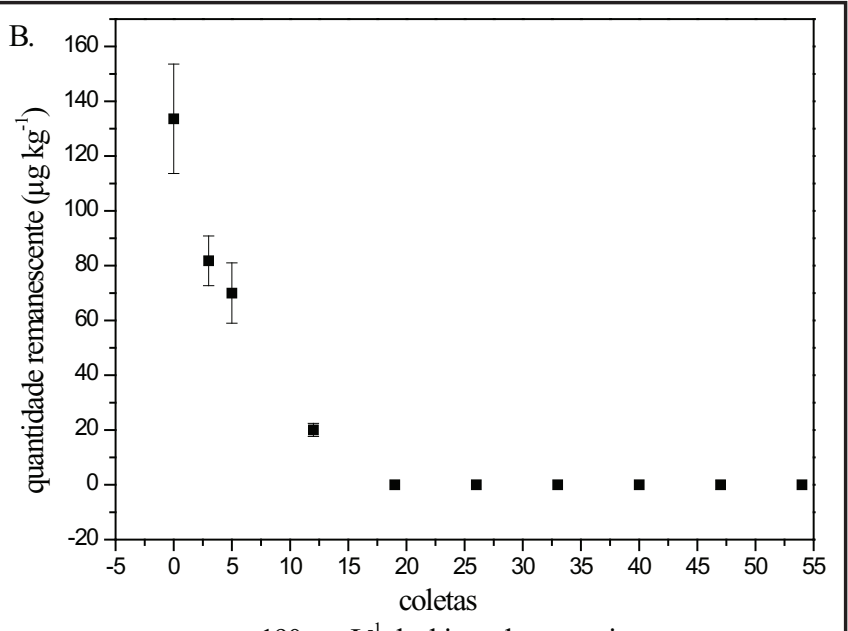

$190 \mathrm{mg} \mathrm{L}^{-1}$ de thiamethoxam ativo

Figura 2 - Teores de thiamethoxam em solo nos tratamentos com aplicação de $380 \mathrm{mg} \mathrm{L}^{-1}$ (A) e $760 \mathrm{mg} \mathrm{L}^{-1}$ (B) de ACTARA $250 \mathrm{WG}$

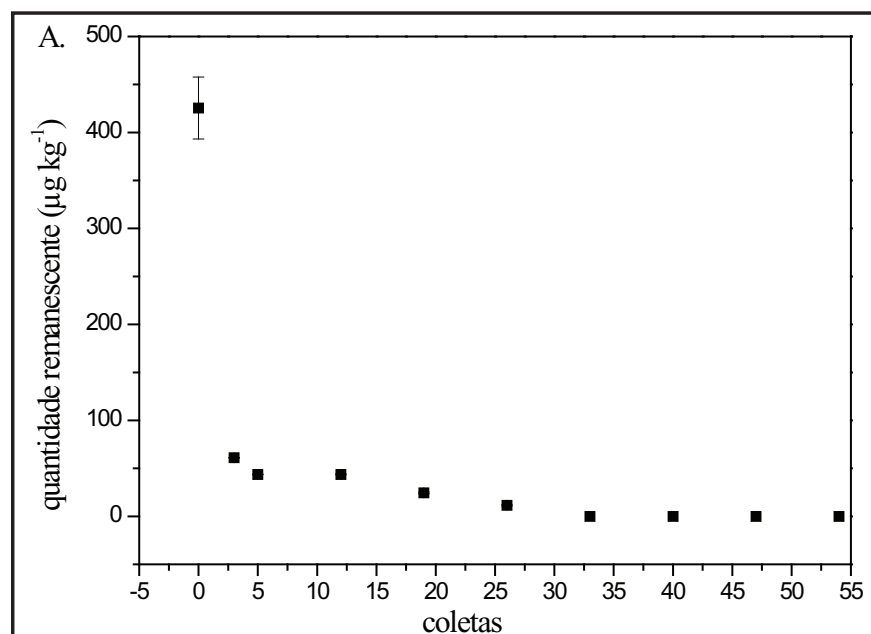

$95 \mathrm{mg} \mathrm{L}^{-1}$ de thiamethoxam ativo

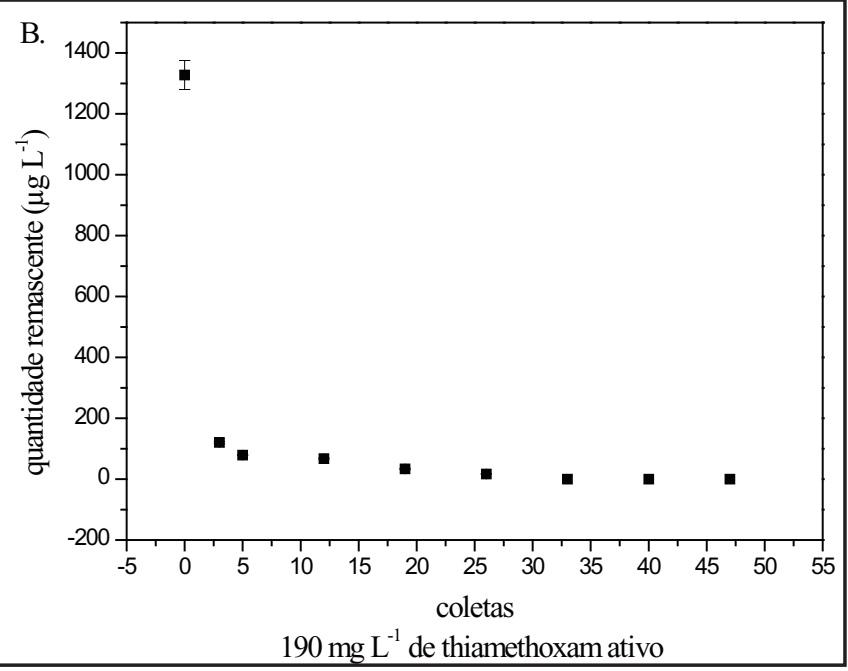

$190 \mathrm{mg} \mathrm{L}^{-1}$ de thiamethoxam ativo

Figura 3 - Teores de thiamethoxam em água nos tratamentos com aplicação de $380 \mathrm{mg} \mathrm{L}^{-1}$ (A) e $760 \mathrm{mg} \mathrm{L}^{-1}$ (B) de ACTARA $250 W G$

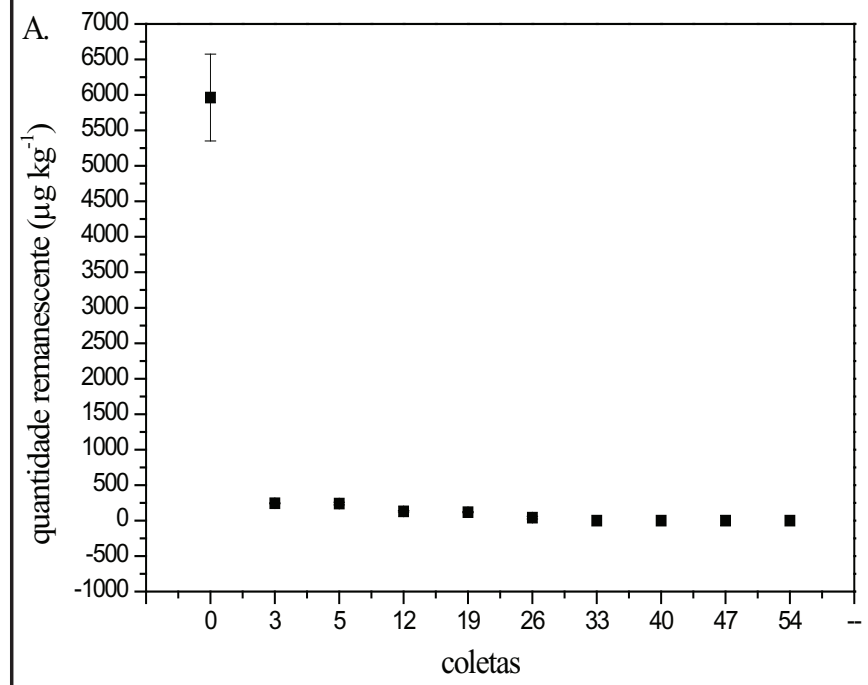

$95 \mathrm{mg} \mathrm{L}^{-1}$ de thiamethoxam ativo

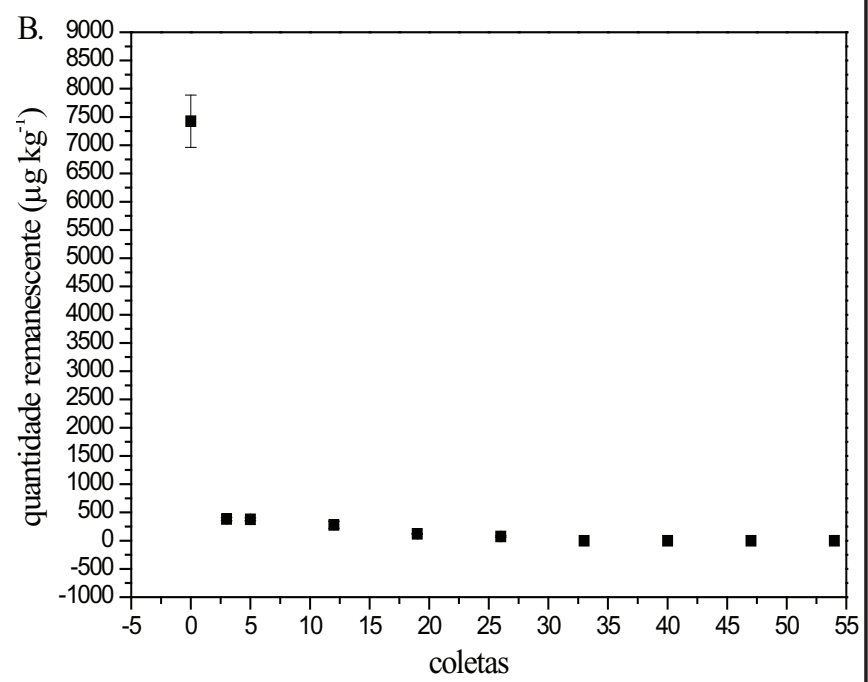

$190 \mathrm{mg} \mathrm{L}^{-1}$ de thiamethoxam ativo

Figura 4 - Teores de thiamethoxam em folhas nos tratamentos com aplicação de $380 \mathrm{mg} \mathrm{L}^{-1}$ (A) e $760 \mathrm{mg} \mathrm{L}^{-1}$ (B) de ACTARA $250 \mathrm{WG}$ 
mentos. Da $3^{\text {a }}$ para a $4^{\text {a }}$ coleta, a queda foi em torno de três vezes em $190 \mathrm{mg} \mathrm{L}^{-1} \mathrm{e}$, em $95 \mathrm{mg} \mathrm{L}^{-1}$, não foi mais detectado no solo o inseticida (Figuras 2A e 2B).

Karmakar e Kulshrestha (2009), em trabalho de persistência do thiamethoxam no tomate e solo de cultivo, verificaram que o inseticida, após 20 dias, não foi mais detectado. O estudo apresentou resultados similares aos obtidos neste trabalho, no qual o thiamethoxam não foi detectado após o $26^{\circ}$ dia, nas matrizes.

Barik et al. (2004) avaliaram a persistência do thiamethoxam em amostras do cultivo de arroz (folhas, grãos e solo), em que as coletas foram realizadas entre 2 h a 15 dias após a aplicação. Os autores observaram que cerca de $60 \%$ do resíduo do inseticida foi dissipado após 5 dias de aplicação e que no $15^{\circ}$ dia, a dissipação foi de até $88 \%$. O estudo de meia-vida foi de 5,2 dias para dose recomendada para o arroz e 5,8 dias para o dobro da dose recomendada.

Na água, da $1^{a}$ para $2^{a}$ coleta, a redução foi de, aproximadamente, 11 vezes $\left(190 \mathrm{mg} \mathrm{L}^{-1}\right)$ ou 7 vezes $(95 \mathrm{mg}$ $\mathrm{L}^{-1}$ ) (Figuras 3A e 3B). Esses valores elevados são, possivelmente, pela fração do inseticida que caiu diretamente sobre a água durante o experimento e o mesmo pode ter sido absorvido pelo solo ou pela planta.

Da $2^{a}$ para a $3^{a}$ coleta, houve uma redução de $34 \%$ (190 mg L $\mathrm{m}^{-1}$ ) e de $28 \%$ (95 mg. $\mathrm{L}^{-1}$ ) de thiamethoxam na água. Da $3^{\mathrm{a}}$ para a $6^{\mathrm{a}}$ coleta, houve um intervalo de quatro semanas e a queda foi em torno de $80 \%$ nos dois tratamentos (190 $\mathrm{mg} \mathrm{L}^{-1}$ e $95 \mathrm{mg} \mathrm{L}^{-1}$ ) (Figuras 3A e 3B).

$A$ rápida dissipação do thiamethoxam no solo, na água e nas folhas, da $1^{\circ}$ para $2^{\circ}$ coleta, podem ser explicadas, principalmente, pela fotodegradação do inseticida, além de outros fatores como volatilização, degradação microbiana ou hidrólise. De acordo com Katagi (2004), a fotodegradação é um dos caminhos mais destrutivos para pesticidas, principalmente nas superfícies das folhas e no solo, após a aplicação.
Peña et al. (2011) descreve que a banda de absorção UV do thiamethoxam é de 250 a 255 nm, estendendo-se para $290 \mathrm{~nm}$, com isso, o inseticida absorve na faixa de luz da troposfera, podendo ser degradado por fotólise direta; desta forma, sugere-se que a dissipação do thiamethoxam, neste trabalho, possa ter ocorrido por fotólise, devido a sua exposição permanente de luz solar na casa de vegetação.

Evidenciou-se, portanto, que a dissipação do thiamethoxam ocorreu primeiramente nas folhas e depois na água e no solo, sendo que após alguns dias não houve mais detecção do inseticida em todo o experimento.

A intensidade de luz solar também pode influenciar a fotodegradação, bem como a presença de ácidos húmicos, óxidos, dentre outros (Castro, 2005). Em trabalho experimental realizado por Peña et al. (2011), observouse que o thiamethoxam em águas residuais, mantido no escuro, em condições anaeróbicas, sofreu um processo de degradação mais lenta do inseticida em comparação com o exposto em luz natural que obteve uma rápida degradação.

Nos rizomas não foi detectada a presença de thiamethoxam (Figura 5B), devido, provavelmente, a baixa concentração do pesticida obtido no solo neste experimento em relação a outras matrizes.

Analisando o perfil cromatográfico das folhas (Figura 5A) e rizomas (Figura 5B) em relação à similaridade da frequência de ocorrência do tempo de retenção, o coeficiente de correlação cofenética foi $R=0,99$ para as folhas e $\mathrm{R}=1$ para os rizomas, demonstrando a confiabilidade do dendrograma (Figura 6).

Empregando-se dados do perfil cromatográfico, observou-se que, nas folhas, nos tratamentos com 95 e $190 \mathrm{mg} \mathrm{L}^{-1}$, os resultados mostraram-se similares, porém, quando comparou-se com os resultados obtidos no controle, observou-se a distante similaridade do controle e das concentrações avaliadas (Figuras 6A e 6B).
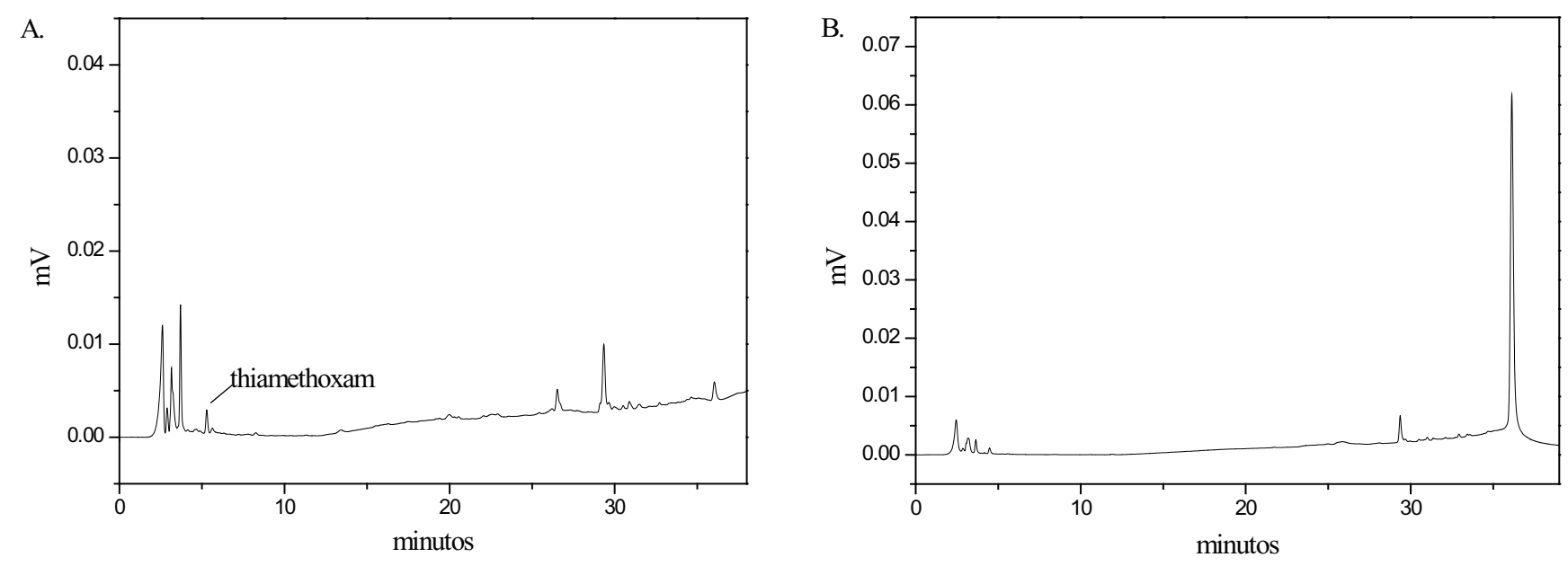

Figura 5 - Perfil cromatográfico das folhas (A) e rizomas (B) de H. coronarium em experimento de cultivo em casa de vegetação 


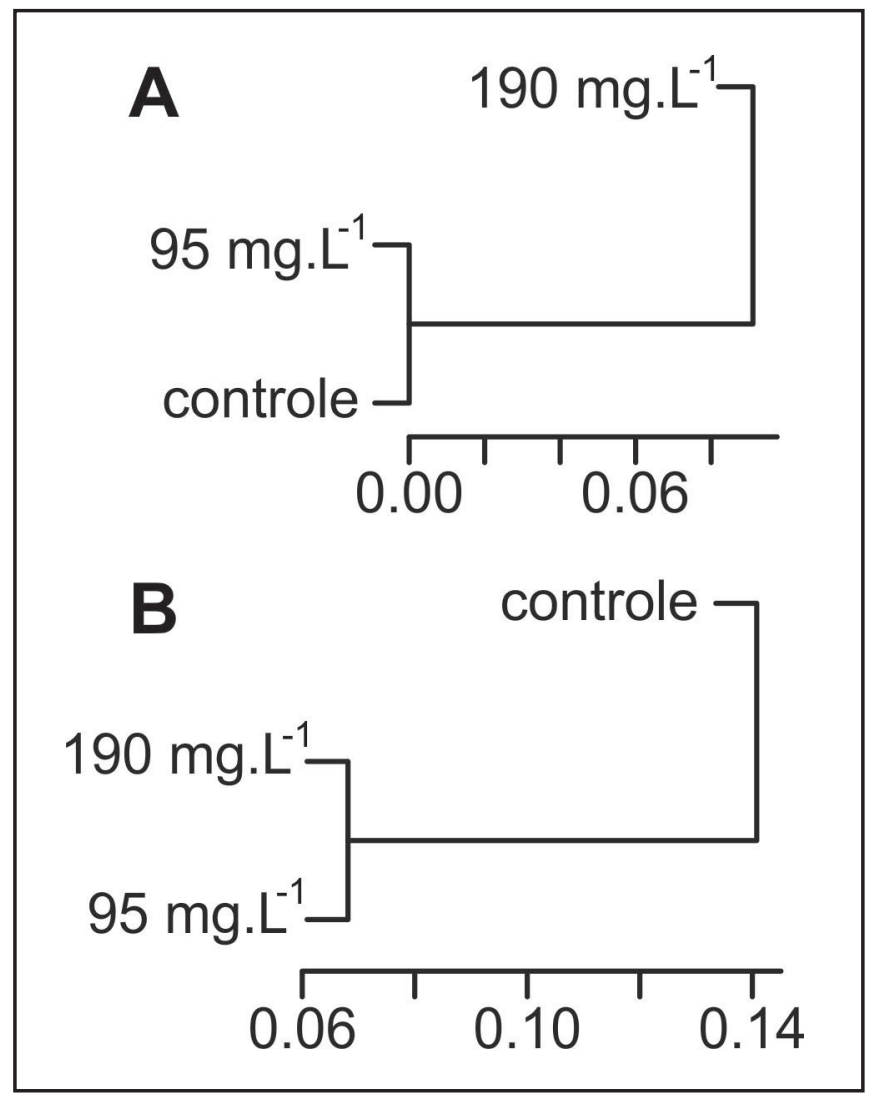

Figura 6. Similaridade da frequência dos picos no perfil cromatográfico de rizomas (A) e folhas (B) nos tratamentos com $95 \mathrm{mg} \mathrm{L}^{-1}$ e $190 \mathrm{mg} \mathrm{L}^{-1}$ de thiamethoxam ativo e no controle

De acordo com os dados representados nas Figuras $6 \mathrm{~A}$ e $6 \mathrm{~B}$, pode-se correlacionar à presença de thiamethoxam como fator limitante da alteração dos metabólitos secundários. Como o inseticida foi aplicado através de pulverização, isso pode ter ocasionado a influência direta nos metabólitos presentes nas folhas.

Um estudo sobre o efeito fisiológico do thiamethoxam na cana-de-açúcar concluiu que o inseticida tem o efeito bioativador, possibilitando o incremento no diâmetro do colmo e na massa seca do sistema radicular da cana (Pereira et al., 2010).

Dan et al. (2012) evidenciaram qualidade fisiológica no desenvolvimento inicial da planta após a aplicação do thiamethoxam. Os resultados obtidos pelos autores corroboram, portanto, com a observação anterior de que o inseticida foi o fator limitante para a distância obtida dos tratamentos 190 e $95 \mathrm{mg} \mathrm{L}^{-1}$, em relação ao controle (Figuras 6A e 6B).

Nos rizomas, o tratamento $95 \mathrm{mg} \mathrm{L}^{-1}$ e o controle, apresentaram similaridade, quanto à frequência dos picos determinados nos perfis cromatográficos; por outro lado, o tratamento $190 \mathrm{mg} \mathrm{L}^{-1}$, manteve-se relativamente distante dos outros dois tratamentos (Figuras 6A e 6B). Evidenciou-se que, nos rizomas, no tratamento de maior concentração, ocorreu a influência na alteração dos metabólitos presentes, apesar de este não ter sido detectado nesta matriz.
A aplicação do thiamethoxam foi realizada através de pulverização, desta forma, a translocação do inseticida na planta pode ter ocorrido via floema e não via xilema, possivelmente, porque no ato de aplicação, o inseticida chegou de forma heterogênea no solo e, a concentração encontrada no solo, foi baixa, em relação às folhas. Torres (2009) cita que inseticidas sistêmicos são transportados via xilema quando aplicados ao solo, portanto, isso explica a não detecção do thiamethoxam nos rizomas de H. coronarium.

Os compostos fenólicos, em muitos vegetais, é que geram o odor, sabor e a coloração, além de serem atrativos para os animais polinizadores ou dispersores de sementes e de desenvolverem função de proteção nas plantas contra os raios UV, insetos, fungos, bactérias e vírus (Peres, 2004). Desta forma, avaliaram-se, nas folhas, os teores de fenóis totais em relação ao controle $\left(309,09\right.$ a 350,82 $\left.\mathrm{gg} \mathrm{kg}^{-1}\right)$ e aos tratamentos $95 \mathrm{mg} \mathrm{L}^{-1}$ $\left(297,92\right.$ a $\left.378,46 \mu \mathrm{g} \mathrm{kg}^{-1}\right)$ e $190 \mathrm{mg} \mathrm{L}^{-1}(309,17$ a 342,92 $\mu \mathrm{g} \mathrm{kg}{ }^{-1}$ ) (Figura 7A). Nos rizomas, as concentrações do controle variaram de 151,90 a 153,15 $\mu \mathrm{g} \mathrm{kg}^{-1}$, sendo que no tratamento $190 \mathrm{mg} \mathrm{L}^{-1}$, a concentração variou de 153,50 a $156,25 \mu \mathrm{g} \mathrm{kg}^{-1} \mathrm{e}$, no tratamento $95 \mathrm{mg} \mathrm{L}^{-1}$, de 153,00 a 154,60 $\mathrm{\mu g} \mathrm{kg}^{-1}$ (Figura 7B).

As folhas apresentaram o thiamethoxam da $1^{\mathrm{a}}$ a $6^{\mathrm{a}}$ coleta e, neste intervalo, houve uma leve oscilação nos valores obtidos de fenóis entre o controle e as duas 


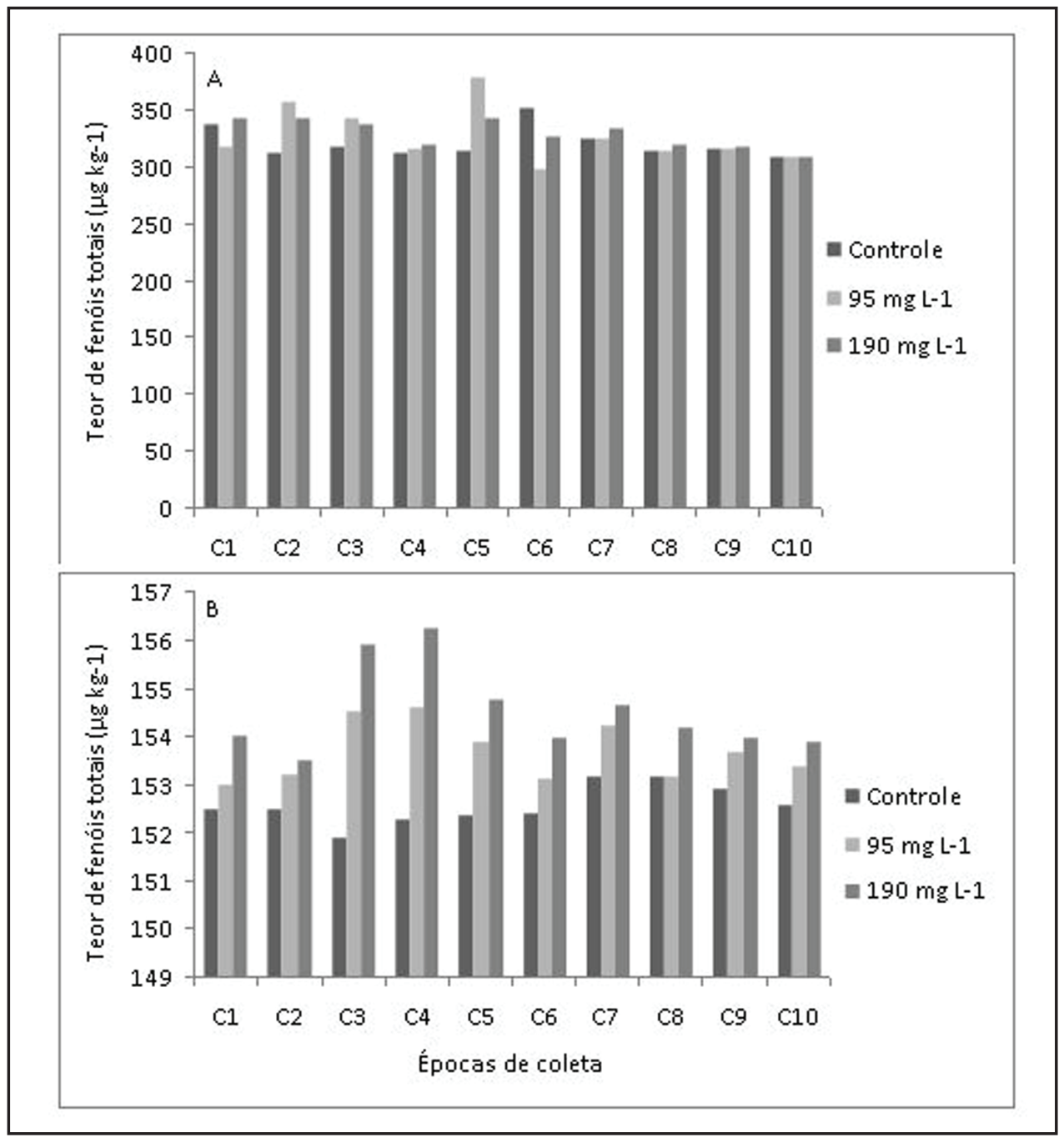

Figura 7. Teores de fenóis totais em folhas (A) e rizomas (B) nos tratamentos com $95 \mathrm{mg} \mathrm{L}^{-1}$ e $190 \mathrm{mg} \mathrm{L}^{-1} \mathrm{de}$ thiamethoxam e no controle. $\mathrm{C} 1=01 \mathrm{~h}, \mathrm{C} 2=3$ dias, $\mathrm{C} 3=5$ dias, $\mathrm{C} 4=12$ dias, $\mathrm{C} 5=19$ dias, $\mathrm{C} 6=26$ dias, $\mathrm{C} 7=33$ dias, $\mathrm{C} 8=40$ dias, $\mathrm{C} 9=47$ dias, $\mathrm{C} 10=54$ dias após a aplicação do inseticida.

concentrações do inseticida utilizadas no experimento (Figura 7A).

Nas folhas, os valores de compostos fenólicos totais, tanto aumentaram quanto diminuíram, em função da presença do inseticida, sendo que, este fato, pode ter ocorrido devido à oscilação representar uma discrepância menor que $10 \%$, o que está na faixa de erro do método. Porém, quando não detectou-se o inseticida, esta oscilação praticamente não foi observada, o que sugere que mesmo em baixos teores de thiamethoxam, a oscilação é resultado da interferência deste no metabolismo da planta (Figura 7A).

Os rizomas não apresentaram concentrações de thiamethoxam, porém, nestas amostras, as oscilações nos conteúdos fenólicos foram maiores do que nas folhas. Nos rizomas, houve uma resposta de aumento do conteúdo fenólico no tratamento de maior concentração e menor resposta no controle em todas as coletas, sendo mais acentuado quando a planta apresentou concentrações de inseticida nas folhas (Figura 7B).
Segundo Treutter (2010), as plantas, em condições de estresse, aumentam ou diminuem as concentrações de compostos fenólicos, de acordo com o tipo de estresse que a planta é submetida, demonstrando que os teores de fenóis na $H$. coronarium podem sofrer influência devido à presença do thiamethoxam.

A presença do thiamethoxam na $H$. coronarium alterou a produção dos metabólitos secundários e gerou oscilações nos teores de compostos fenólicos presentes na espécie. Essas mudanças detectadas, podem agir no metabolismo da planta, alterando as interações da espécie com seus polinizadores e na fauna associada.

Os resultados obtidos neste estudo demonstram a importância de pesquisas com inseticidas e a compreensão da relação com organismos vivos, já que estes são primordiais para a conservação da biodiversidade de ambientes expostos a estes e a outros tipos de contaminantes. 


\section{Conclusão}

O thiamethoxam foi detectado no solo, nas folhas e na água, porém, nos rizomas não se observou a presença do mesmo.

Os compostos fenólicos da Hedychium coronarium (folhas e rizomas) apresentaram oscilações em sua concentração nos tratamentos com aplicação de de thiamethoxam.

Foi observada a influência do inseticida na similaridade de frequência dos picos no perfil cromatográfico das folhas e rizomas, onde nos rizomas essa influência ficou mais evidente no tratamento com concentração de $190 \mathrm{mg} \mathrm{L}^{-1}$.

\section{Agradecimentos}

À Fundação de Apoio ao Desenvolvimento do Ensino, Ciência e Tecnologia do Estado de Mato Grosso do Sul (FUNDECT) pelo incentivo financeiro e pela bolsa de mestrado e ao Conselho Nacional de Desenvolvimento Científico e Tecnológico (CNPq).

\section{Referências}

ALMEIDA, R. A.; ALMEIDA, N. A. M. Remoção de coliformes do esgoto por meio de espécies vegetais. Revista Eletrônica de Enfermagem, v.7, p.306-317, 2005.

ALMEIDA, R. DE A.; OLIVEIRA, L. F. C. DE; KLIEMANN, H. J. Eficiência de espécies vegetais na purificação de esgoto sanitário. Pesquisa Agropecuária Tropical, v.37, n.1, p.1-9, 2007.

BARIK, A.; BHATTACHARYA, B.; LASKAR, S. BANERJEE; T.C. The determination of $n$-alkanes in the cuticular wax of leaves of Ludwigia adscendens L. Phytochemical Analysis, v.15, p.109-11, 2004.

BIERNACKI, M.; LOVETT-DOUST, J. Vallisneria americana (Hydrocharitaceae) as biomonitor of aquatic ecosystems: comparison of cloned genotypes. American Journal of Botany, v.84, p.1743-1751, 1997.

CARVAlHO, N. L.; PERLIN, R. S.; COSTA, E. C. Thiamethoxam em tratamento de sementes. Monografias Ambientais, v.2, n.2, p.158-175, 2011.

CASTRO, N. R. A. Sorção, degradação e lixiviação do inseticida thiamethoxam em latossolo e argissolo. Lavras: UFLA, 2005. 161p. Tese Doutorado.

DAN, L. G. DE M.; DAN, H. DE A.; PICCININ, G. G.; RICCI, T. T.; ORTIZ, L. H. T. Tratamento de sementes com inseticida e a qualidade fisiológica de sementes de soja. Caatinga, v.25, p.45-51, 2012.

DJERIDANE, A., YOSFEI, M., NADJEMI, B, BOUTASSOUNA, D., STOCKER, P.; VIDAL, N. Antioxidant activity of some segerium medicinal plants extracts containing phenolic compounds. Food Chemistry, v.97, p.654-660, 2006.

EVERARD, P.; DENNY, P. Flux of lead in submerged plants and its relevance to a freshwater system. Aquatic Botany, v.21, p.181-193, 1985.

KARMAKAR, R.; KULSHRESTHA, G. Persistence, metabolism and safety evaluation of thiamethoxam in tomato crop. Pest Management Science, v.65, p.931-937, 2009.

KATAGI, T. Photodegradation of pesticides on plant and soil surfaces. Reviews of Environmental Contamination and Toxicology, v.182, p.1-195, 2004.

KIMA, H-J; SHELVER, W. L.; HWANG, E-C; XUA, TING; LI, Q. X. Automated flow fluorescent immunoassay for part per trillion detection of the neonicotinoid insecticide thiamethoxam. Analytica Chimica Acta, v.571, p.66-73, 2006.

LAMEGO, F. P.; VIDAL, A. V. Fitorremediação: plantas como agentes de despoluição? Pesticidas: Revista de Ecotoxicologia e Meio Ambiente, v.17, p.9-18, 2007.

LIQING, Z.; GUOGUANG, L.; DEZHI, S.; KUN, Y. Hydrolysis of thiamethoxam. Bulletin of Environmental Contamination and Toxicology, v.76, p.942-949, 2006.

MACEDO, W. R.; CASTRO, P. R. DE C. Thiamethoxam: Molecule moderator of growth, metabolism and production of spring wheat. Pesticide Biochemistry and Physiology, v.100, p.299-304, 2011.

MATSUDA, H.; MORIKAWA, T.; SAKAMOTO, Y.; TOGUCHIDA, I.; YOSHIKAWA, M. Labdane-type diterpenes with Inhibitory effects on Increase in vascular permeability and nitric oxide production from Hedychium coronarium. Bioorganic \& Medicinal Chemistry, v.10, p.2527-2534, 2002.

PEÑA, A.; RODRÍGUEZ-LIÉBANA, J. A.; MINGORANCE, M. D. Persistence of two neonicotinoid insecticides in wastewater, and in aqueous solutions of surfactants and dissolved organic matter. Chemosphere, v.84, p.464-470, 2011.

PEREIRA, J. M.; FERNANDES, P. M.; VELOSO, V. R. S. Efeito fisiológico do inseticida thiamethoxam na cultura da cana-de-açúcar. Arquivo do Instituto Biológico, v.1, p.154-164. 2010. 
PERES, L. E. P. Metabolismo secundário. Piracicaba: ESALQ/USP, 2004. p.1-10.

PUSSENTE, I. G. Extração sólido-líquido e partição em baixa temperatura (ESL-PBT) de Clorpiriflós, thiamethoxam e deltramitrina em maça e análise por cromatografia gasosa. Viçosa : UFV, 2008. 62p. Dissertação Mestrado

RANCAN, M.; ROSSI, S.; SABATINI, A. G. Determination of Thiamethoxam residues in honeybees by high performance liquid chromatography with an electrochemical detector and post-column photochemical reactor. Journal of Chromatography, v.1123, p.60-65, 2006.

R DEVELOPMENT CORE TEAM. R: A Language and Environment for Statistical Computing. R Foundation for Statistical Computing, Vienna, Austria, 2011. ISBN 3-900051-07-0. Disponível em: <http://www.R-project. org. Acesso em: 12 Nov. 2011.

SANTOS, S. B.; PEDRALLI, G; MEYER, S. T. Aspectos da fenologia e ecologia de Hedychium coronarium (Zingiberaceae) na Estação ecológica do Tripuí, Ouro Preto-MG. Planta Daninha, v.23, p.175-180, 2005.

SCHWARTZ, B. J.; SPARROW, F. K.; HEART, N. E.; THEDE, B. M. Simultaneous, derivatization and trapping of volatile products from aqueous photolysis of thiamethoxam insecticide. Journal Agricultural and Food Chemistry, v.48, p.4671-4675, 2000.

TORRES, F. Z. V. Translocação do inseticida thiamethoxam no floema de mamoeira e cafeeira. Lavras: UFLA, 2009. 105p. Tese Doutorado

TREUTTER, D. Managing Phenol Contents in Crop Plants by Phytochemical Farming and Breeding-Visions and Constraints. International Journal of Molecular Sciences, v.11, p.807-857, 2010. 